\title{
FOSFITOS E PRODUTOS Á BASE DE EXTRATOS VEGETAIS NO CONTROLE DA FERRUGEM DO TRIGO
}

Rosana Taschetto Vey ${ }^{1}$, Ketlen Raisa Rey Rodrigues ${ }^{2}$, Amanda dos Santos Hajar ${ }^{3}$, Luana da Silva Cadore ${ }^{4}$

${ }^{1}$ Mestranda do Programa de Pós-Graduação em Agrobiologia do Departamento de Biologia da Universidade Federal de Santa Maria, (rosanatv2103@yahoo.com.br) Santa Maria, RS

${ }^{2}$ Aluna do curso de graduação em Agronomia da Universidade Federal do Pampa Campus Itaqui, RS

${ }^{3}$ Aluna do curso de graduação em Agronomia da Universidade Federal do Pampa Campus Itaqui, RS

${ }^{4}$ Mestranda do Programa de Pós-Graduação em Agrobiologia do Departamento de Biologia da Universidade Federal de Santa Maria, Santa Maria, RS

Recebido em: 08/04/2017 - Aprovado em: 10/06/2017 - Publicado em: 20/06/2017 DOI: 10.18677/EnciBio_2017A56

\section{RESUMO}

O objetivo deste trabalho foi verificar a influência de fosfitos e produtos à base de extratos vegetais na severidade da ferrugem na folha do trigo e, a partir dos dados obtidos calcular a área abaixo da curva de progresso da doença. O experimento foi realizado na área experimental da Unipampa, Campus Itaqui, com delineamento em blocos ao acaso, sendo dez tratamentos e quatro repetições. Utilizou-se a cultivar de trigo TBIO Iguaçu e, os tratamentos consistiram dos produtos Reforce $\mathrm{Cu}^{\circledR}$ (Fosfito de $\mathrm{K}+\mathrm{Cu}$ ), Reforce $\mathrm{Zn}^{\circledR}$ (Fosfito de $\mathrm{Zn}$ ), Fortaleza ${ }^{\circledR}$ (Fosfito de $\mathrm{K}+$ composto cítrico), Nutriphite $^{\circledR}$ (Fosfito de K), Fulland ${ }^{\circledR}$ (Fosfito de Cu), Green Force $S^{\circledR}$ (Subproduto da lavoura cafeeira + compostos cítricos), Green Force $\mathrm{V}^{\circledR}$ (Subproduto da lavoura cafeeira + fosfito de K) e Green Fós ${ }^{\circledR}$ (Fosfito de K) e testemunhas (com e sem fungicida). Iniciou- se as aplicações 60 dias após a semeadura, com uma pulverização a cada 20 dias, totalizando três aplicações. As avaliações iniciaram 75 dias após a semeadura onde, avaliou- se semanalmente a incidência e severidade de dez plantas inteiras e dez folhas bandeiras por parcela, totalizando cinco avaliações. Para a avaliação da severidade utilizou-se escala diagramática de COBB. Com os dados de severidade foi determinada a área abaixo da curva de progresso da doença. O fungicida foi o mais eficiente no controle da ferrugem seguido dos tratamentos com Fortaleza ${ }^{\circledR}$, Reforce $\mathrm{Zn}^{\circledR}$, Green Force $\mathrm{S}^{\circledR}$ e Fulland ${ }^{\circledR}$. São necessários mais trabalhos para comprovar a eficiência destes produtos como alternativa no controle da ferrugem.

PALAVRAS-CHAVE: Produtos alternativos, Puccinia recondita f. sp. tritici; TBIO Iguaçu. 


\title{
PHOSPHITES AND VEGETAL EXTRACTS BASED PRODUCTS IN RUST OF WHEAT CONTROL
}

\begin{abstract}
The objective of this work was to verify the influence of phosphites and products based on plant extracts on the severity of rust on the wheat leaf and from the data obtained calculate the area below the disease progress curve. The experiment was carried out in the experimental area of Unipampa, Campus Itaqui, with a randomized block design, with ten treatments and four replications. Wheat cultivar TBIO Iguaçu was used, and the treatments consisted of the products Reforce $\mathrm{Cu} \AA$, Reforce $\mathrm{Zn} \AA$ (Zn Phosphite), Fortaleza® (K Phosphite + citric compound), Nutriphite® ${ }^{\circledR}$ ( K Phosphite), Fulland® (Cu Phosphite), Green Force $\mathrm{S} B$ (By-product of coffee cultivation + citrus compounds), Green Force V® (By-product of coffee cultivation + K phosphite) and Green Fos ${ }^{\circledR}$ (Phosphite K) And witnesses (with and without fungicide). The applications were started 60 days after sowing, with one spray every 20 days, totaling three applications. The evaluations began 75 days after sowing, where the incidence and severity of ten whole plants and ten leaflets per plot were evaluated weekly, totaling five evaluations. For the severity assessment, a diagrammatic COBB scale was used. With severity data the area under the disease progress curve was determined. The fungicide was the most efficient in rust control followed by treatments with Fortaleza®, Reforce $\mathrm{Zn} \AA$, Green Force ${ }^{\circledR}$ and Fulland®. More work is needed to prove the efficiency of these products as an alternative to rust control.
\end{abstract}

KEYWORDS: Alternative products; Puccinia recondita f . sp. tritici ; TBIO Iguaçu.

\section{INTRODUÇÃO}

O trigo (Triticum aestivum L.) é um dos cereais mais cultivados e importantes do mundo, representando aproximadamente $30 \%$ da produção mundial de grãos. É uma cultura de grande importância para o Brasil, havendo no país uma demanda crescente por derivados desse cereal (SEAB/ DERAL, 2013). É considerado um cereal de importância significativa na alimentação da humanidade e no Brasil este cereal é cultivado principalmente no estado do Paraná, Rio Grande do Sul e Santa Catarina, sendo estes três estados responsáveis por $90 \%$ da produção brasileira (CAMPONOGARA, et al., 2015).

De acordo com a Companhia Nacional de Abastecimento - CONAB (2017) a área cultivada com trigo no Brasil na safra $2016 / 2017$ foi de 2,1 milhões de hectares, onde a produtividade média no país foi de $2.667 \mathrm{~kg} / \mathrm{ha}^{-1}$ e a produção total de 5,6 milhões de toneladas deste cereal. No Rio Grande do Sul (RS), a área semeada com trigo na safra 2016/2017 foi de 776,9 mil ha $^{-1}$, mantendo-se a mesma da safra 2015/2016. A produção total no RS foi de 1,8 milhões de toneladas, representando $27,3 \%$ inferior a produção da safra passada (CONAB, 2017).

São vários os fatores responsáveis pela diminuição da produtividade na cultura do trigo. Segundo GULART et al. (2013), nos últimos anos houve um aumento na intensidade de doenças nas lavouras de Triticum aestivum L., causando redução de produtividade e da área cultivada. Dentre as doenças foliares que atacam a cultura do trigo, na região Sul do Brasil à um destaque para ocorrência de ferrugem da folha e mancha amarela (TORMEN et al., 2013).

A ferrugem da folha do trigo (Puccinia recondita f. sp. tritici.), ataca a planta nos vários estágios de desenvolvimento desta e a intensidade varia dependendo da suscetibilidade do cultivar utilizado, da virulência da raça fisiológica do patógeno e 
das condições ambientais (ASSUNÇÃO \& TORRES, 2013). Para tentar controlar a ferrugem da folha do trigo e outras doenças, muitos métodos estão sendo utilizados como, uso de cultivares resistentes, sementes sadias, rotação de culturas e aplicação de fungicidas (MORALES, et al., 2012).

Com a crescente preocupação com o meio ambiente e com a obtenção de produtos agrícolas livres de agrotóxicos, o uso de métodos alternativos de controle de doenças vem se tornando uma realidade. Assim, o objetivo deste trabalho foi verificar a influência de fosfitos e produtos à base de extratos vegetais na severidade da ferrugem na folha do trigo cultivar TBIO Iguaçu e, a partir dos dados obtidos calcular a área abaixo da curva de progresso da doença.

\section{MATERIAL E MÉTODOS}

O município de Itaqui se encontra na Latitude $29^{\circ} 07^{\prime} 17^{\prime \prime}$ Sul e Longitude $56^{0}$ 33' 24" Oeste, com 72m de altitude em relação ao nível do mar (GOOGLE EARTH, 2017). O experimento foi realizado na área experimental da Universidade Federal do Pampa - Unipampa/ Campus Itaqui. Para a execução deste trabalho foi utilizada a cultivar de trigo TBIO Iguaçu, cultivar moderadamente suscetível à ferrugem. A cultivar de trigo TBIO Iguaçu apresenta hábito vegetativo intermediário, perfilhamento forte, porte médio/alto e ciclo médio (BIOTRIGO, 2013).

O delineamento experimental foi de blocos ao acaso, com sete tratamentos utilizando produtos à base de extratos vegetais e fosfitos, uma testemunha com aplicação de fungicida e outra sem a aplicação de fungicida, totalizando dez tratamentos e quatro repetições. Cada parcela foi composta por nove linhas com espaçamento $17 \mathrm{~cm}$ entre elas, cinco metros de comprimento, totalizando 7,65 $\mathrm{m}^{2}$ cada parcela.

A semeadura foi realizada no dia 14 de junho de 2013, com uma densidade de sementes de $350 \mathrm{~kg} / \mathrm{ha}$. A adubação foi realizada juntamente com a semeadura, utilizando $310 \mathrm{~kg} / \mathrm{ha}$ de adubo na fórmula 05.20.20. A adubação de cobertura foi feita com $150 \mathrm{~kg} / \mathrm{ha}$ de uréia (45\% nitrogênio), aplicada à lanço no estádio 3, de acordo com os estádios de desenvolvimento baseados na escala de Zadoks (ZADOKS et al., 1974). O estádio 3 representa o elongamento do colmo, a segunda aplicação foi de $80 \mathrm{~kg} / \mathrm{ha}$ no estádio de emborrachamento das plantas (estágio 4).

A escala Zadoks (tabela 1) é frequentemente usada no cultivo de trigo e descreve os estádios morfológicos externos que envolvem o crescimento e desenvolvimento das plantas. Esta escala tem 10 etapas numeradas 0-9 que descrevem a cultura (ZADOKS et al., 1974).

TABELA 1 - Estádios de desenvolvimento do trigo de acordo com a Escala de Zadoks (ZADOKS et al., 1974).

\begin{tabular}{c|c|c}
\hline Etapa principal & Descrição & Sub- fase \\
\hline 0 & Germinação & $0.0-0.09$ \\
\hline 1 & Produção de folhas & $1.0-1.9$ \\
\hline 2 & Perfilhamento & $2.0-2.9$ \\
\hline 3 & Elongamento do colmo & $3.0-3.9$ \\
\hline 4 & Emborrachamento & $4.0-4.9$ \\
\hline 5 & Emergência da inflorescência & $5.0-5.9$ \\
\hline 6 & Florescimento (antese) & $6.0-6.9$ \\
\hline 7 & Acúmulo de leite no grão & $7.0-7.9$ \\
\hline 8 & Desenvolvimento farináceo & $8.0-8.9$ \\
\hline 9 & Pós maturação fisiológica do grão & $9.0-9.9$ \\
\hline
\end{tabular}


Os tratamentos testados foram (Tabela 2):

TABELA 2 - Fosfitos e produtos à base de extratos vegetais utilizados nos diferentes tratamentos.

\begin{tabular}{|c|c|c|c|}
\hline Tratamentos & Empresa & Composição & $\operatorname{Dose}^{\star}(\mathrm{mL})$ \\
\hline Reforce Cuß & Agrichem do Brasil & Fosfito de $\mathrm{K}+\mathrm{Cu}$ & 5 \\
\hline Reforce $\mathrm{Zn} \circledast$ & Agrichem do Brasil & Fosfito de $\mathrm{Zn}$ & 3 \\
\hline Fortaleza® & Agrichem do Brasil & $\begin{array}{l}\text { Fosfito de } \mathrm{K}+\text { composto } \\
\text { cítrico }\end{array}$ & 3 \\
\hline Nutriphite® & Ihara Bras & Fosfito de K & 5 \\
\hline Fulland® & $\begin{array}{l}\text { Sudoeste } \\
\text { Agropecus }\end{array}$ & Fosfito de $\mathrm{Cu}$ & 5 \\
\hline GreenForceSß & Agrofitness & $\begin{array}{l}\text { Produto à base de extrato de } \\
\text { subproduto da lavoura } \\
\text { cafeeira + compostos cítricos }\end{array}$ & 10 \\
\hline GreenForceV® & Agrofitness & $\begin{array}{l}\text { Produto à base de extrato de } \\
\text { subproduto da lavoura } \\
\text { cafeeira + fosfito de potássio }\end{array}$ & 10 \\
\hline Green Fós® & Agrofitness & Fosfito de K & 5 \\
\hline
\end{tabular}

* As doses foram utilizadas para cada um litro de água, no preparo da calda.

Além dos tratamentos com produtos à base de extratos vegetais e fosfitos, teve-se também uma testemunha com aplicação de fungicida Nativo (Trifloxistrobina Tebuconazol 0,6 L ha ${ }^{-1}$ ) e Priori Xtra (Azoxistrobina Ciproconazol 0,3 L ha ${ }^{-1}$ ), totalizando 10 tratamentos.

Iniciou-se os tratamentos através de pulverização de fosfitos, produtos à base de extratos vegetais e fungicidas sessenta dias após a semeadura, momento em que ocorreu o início do perfilhamento da cultura. As aplicações foram realizadas com pulverizador costal, com volume de calda de 2,5 L por parcela para os fosfitos e fungicidas. Realizou-se uma aplicação a cada vinte dias, totalizando três aplicações. As duas primeiras aplicações de fungicidas foram realizadas com Priori Xtra ${ }^{\circledR}$ que é um fungicida sistêmico do grupo químico Azoxistrobina: estrobilurina; Ciproconazol: triazol, na dose de $300 \mathrm{~mL} \mathrm{ha}^{-1}$ de produto, com um volume de calda de $150 \mathrm{~L} \mathrm{ha}^{-1}$ de água. Para a última aplicação de fungicida, utilizou-se o fungicida Nativo ${ }^{\circledR}$ também pertencente ao grupo das estrobilurina e triazol, na dose de $600 \mathrm{~mL}^{\text {ha }}{ }^{-1} \mathrm{com}$ um volume de calda de $200 \mathrm{~L} \mathrm{ha}^{-1}$, ambos registrados no Ministério da Agricultura, Pecuária e Abastecimento (MAPA), para o controle da ferrugem da folha do trigo.

Aos setenta e cinco dias após a semeadura, com as plantas no estádio de elongamento do colmo que corresponde ao estádio fenológico 3 de acordo com a Escala de Zadoks, iniciou-se as avaliações de incidência e severidade da ferrugem. A última avaliação foi realizada no estádio de desenvolvimento 7 , momento em que ocorre o acúmulo de leite no grão. Para a avaliação da severidade foi utilizada a escala diagramática de COBB modificada por BARCELOS (1982) para a ferrugem do trigo. As avaliações ocorreram semanalmente, em dez folhas bandeiras e dez plantas por parcela, totalizando 5 avaliações.

A partir dos dados da severidade da folha bandeira e da planta inteira foi calculada a área abaixo da curva de progresso da doença (AACPD), pela equação proposta por SHANER \& FINNEY (1977) descrita abaixo.

$\mathrm{n}-1$

$\mathrm{AACPD}=\Sigma[(\mathrm{yi}+\mathrm{yi}+1) / 2) \times(\mathrm{ti}+1-\mathrm{ti})]$ 
Onde:

n é o número de avaliações;

y a intensidade de doenças;

t o tempo quando da avaliação da intensidade da doença;

i e i+1 representam as observações de 1 a $n$.

Os dados foram submetidos à análise de variância pelo teste $\mathrm{F}$ e as médias agrupadas pelo teste de Scott \& Knott a 5\% de probabilidade. As análises foram realizadas pelo programa estatístico Sisvar (FERREIRA, 2008).

\section{RESULTADOS E DISCUSSÃO}

Nas avaliações de severidade da ferrugem do trigo realizadas na folha bandeira, apenas o Green Force $\mathrm{V}^{\circledR}$ (produto à base de extrato de lavoura cafeeira), não diferiu estatisticamente da testemunha sem aplicação (Tabela 3), porém diferiu das testemunhas com aplicação dos fungicidas.

TABELA 3 - Área abaixo da curva de progresso da ferrugem da folha do trigo (Puccinia recondita f. sp. tritici), na folha bandeira após aplicação de diferentes fontes de fosfitos e de produtos à base de extratos de lavoura cafeeira, na cultura do trigo, cultivar TBIO Iguaçu. Safra 2013. Itaqui, RS.

\begin{tabular}{|c|c|c|c|}
\hline Tratamentos & Composição & Dose (mL/L) & Ferrugem da folha \\
\hline $\begin{array}{l}\text { Testemunha } \\
\text { Sem aplicação }\end{array}$ & & & $42,00 \mathrm{~b}$ \\
\hline $\begin{array}{l}\text { Testemunha com } \\
\text { aplicação }\end{array}$ & $\begin{array}{l}\text { Nativo }^{\circledR} \\
\text { Priori Xtra }{ }^{\circledR}\end{array}$ & $\begin{array}{l}0,6 \mathrm{~L} / \mathrm{ha} \\
0,3 \mathrm{~L} / \mathrm{ha}\end{array}$ & $36,77 \mathrm{a}$ \\
\hline $\begin{array}{l}\text { Reforce } \mathrm{Zn}^{\circledR} \\
\text { Fulland }^{\circledR}\end{array}$ & $\begin{array}{l}\text { Fosfito de } \mathrm{Zn} \\
\text { Fosfito de } \mathrm{Cu}\end{array}$ & $\begin{array}{l}3 \\
5\end{array}$ & $\begin{array}{l}35,80 \mathrm{a} \\
37,15 \mathrm{a}\end{array}$ \\
\hline Green Force $S^{\circledR}$ & $\begin{array}{l}\text { Produto à base de extrato de } \\
\text { subproduto da lavoura } \\
\text { cafeeira }+ \\
\text { Composto cítrico }\end{array}$ & 10 & $35,45 \mathrm{a}$ \\
\hline Fortaleza $^{\circledR}$ & $\begin{array}{l}\text { Fosfito de potássio + } \\
\text { composto cítrico }\end{array}$ & 3 & $38,37 \mathrm{a}$ \\
\hline Nutriphite $^{\circledR}$ & $\begin{array}{l}\text { Fosfito de Potássio } \\
\text { Fosfito de potássio + cobre }\end{array}$ & 5 & $38,50 \mathrm{a}$ \\
\hline Reforce $\mathrm{Cu}^{\circledR}$ & & 5 & $38,60 \mathrm{a}$ \\
\hline Green Fós ${ }^{\circledR}$ & Fosfito de potássio & 5 & $38,75 \mathrm{a}$ \\
\hline Green Force $\mathrm{V}^{\circledR}$ & $\begin{array}{l}\text { Produto à base de extrato } \\
\text { de subproduto da lavoura } \\
\text { cafeeira }+ \\
\text { Fosfito de potássio }\end{array}$ & 10 & $40,30 \mathrm{~b}$ \\
\hline CV\% & & & 12,86 \\
\hline
\end{tabular}

Médias seguidas de letras distintas na mesma coluna diferem estatisticamente entre si pelo teste de Scott \& Knott a $5 \%$ de probabilidade. 
Como a severidade da doença foi baixa nas avaliações da folha bandeira (menor que 5\%) em todos os tratamentos, não foi possível observar diferenças entre os mesmos. Todos os tratamentos com fosfitos, produtos à base de extratos vegetais foram mais eficientes do que o tratamento testemunha sem aplicação, porém foram significativamente inferiores ao tratamento testemunha com aplicação de fungicida.

Para avaliação da planta inteira, o tratamento com fungicidas foi o que mais reduziu a severidade da doença. Os tratamentos com Fortaleza ${ }^{\circledR}$, Reforce $\mathrm{Zn}^{\circledR}$, Green Force $S^{\circledR}$ e Fulland ${ }^{\circledR}$, não apresentaram diferenças entre eles, com redução de $20 \%, 18 \%, 16 \%$ e $15 \%$, respectivamente da AACPD, quando comparados com a testemunha. $\mathrm{O}$ Green Force $\mathrm{V}^{\circledR}$, Nutriphite ${ }^{\circledR}$, Green Fós ${ }^{\circledR}$ e Reforce $\mathrm{Cu}^{\circledR}$ apresentaram a menor redução da severidade da doença (Tabela 4).

TABELA 4 - Área abaixo da curva de progresso da ferrugem da folha do trigo (Puccinia recondita f. sp. tritici), na planta inteira após aplicação de diferentes fontes de fosfitos e produtos à base de extratos vegetais, na cultura do trigo, cultivar TBIO Iguaçu. Safra 2013. Itaqui, RS.

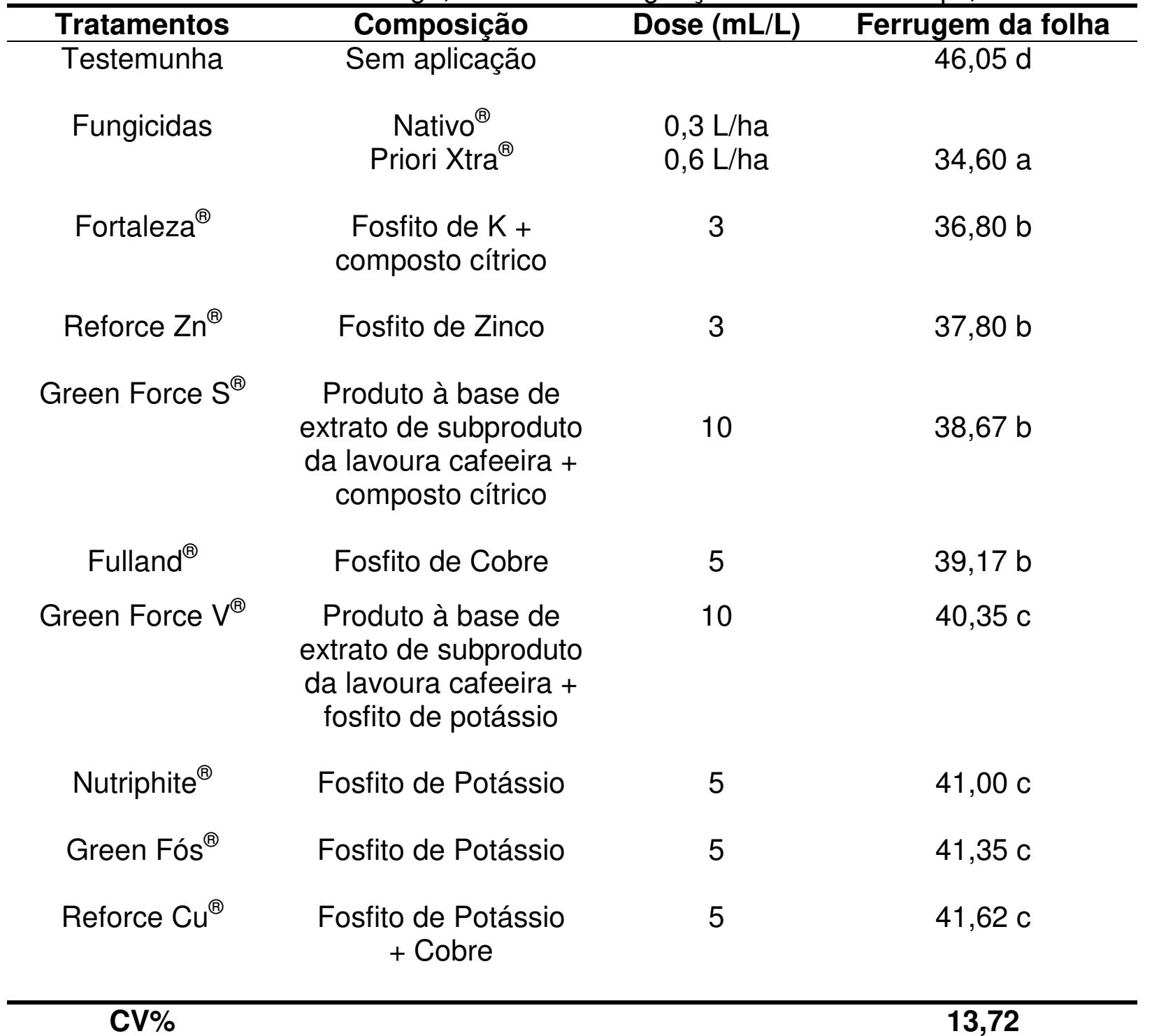

*Médias seguidas de mesma letra na coluna não diferem estatisticamente entre si pelo teste de Scott \& Knott a $5 \%$ de probabilidade. 
A folha bandeira é utilizada como padrão para as avaliações de severidade da ferrugem do trigo. No entanto, a maior severidade desta doença ocorre nas folhas mais velhas. Assim, o Green Force $V^{\circledR}$, para as avaliações da folha bandeira, não reduziu estatisticamente a AACPD quando comparando com a testemunha. Porém, na análise da planta inteira, este produto obteve uma menor AACPD.

Os tratamentos com fosfito de potássio (Nutriphite ${ }^{\circledR}$ e Green fós ${ }^{\circledR}$ ) utilizados de forma isolada, não foram tão eficientes na redução na severidade da ferrugem da folha do trigo na planta inteira, quando comparando com o fosfito de potássio aplicado juntamente com composto cítrico $\left(\right.$ Fortaleza ${ }^{\circledR}$ ). Na cultura do feijão comum (Phaseolus vulgaris), a utilização de fosfitos reduziu a severidade da antracnose de acordo com trabalho realizado por GADAGA et al. (2017), segundo estes autores, os fosfitos utilizados podem ser considerados um método alternativo de controle. Já para BUFFARA et al. (2013), o uso de fosfito de potássio em folhas de videira em pré e pós-infecção pode reduzir o ataque de Phakopsora euvitis em aproximadamente $50 \%$ quando comparado ao tratamento com tebuconazol.

Assim como o fosfito de potássio, os produtos à base de extrato de subproduto da lavoura cafeeira apresentaram uma maior redução da severidade da doença quando associados com subprodutos da indústria de citros (Green Force $S^{\circledR}$ ). Vários trabalhos demonstram o potencial desses compostos cítricos no controle de doenças de plantas. ROSA et al. (2007) verificaram que a aplicação do produto comercial Ecolife $^{\circledR}$ (produto a base de polpa cítrica) em videiras reduziu a severidade do míldio da videira (Plasmopara viticola).

TOFOLI et al. (2012), relatam em seu trabalho sobre a utilização de fosfito de potássio em mistura com o mancozebe para o manejo da requeima do tomateiro, cuja mistura proporcionou aumento significativo do controle desta doença. $\mathrm{O}$ fosfito de zinco (Reforce $\mathrm{Zn}^{\circledR}$ ) e o fosfito de cobre $\left(\right.$ Fulland ${ }^{\circledR}$ ) reduziram a severidade da ferrugem do trigo. Os fosfitos de cobre e de zinco reduziram a severidade de oídio em mudas de eucalipto, mostrando-se eficientes no controle desta doença (SILVA et al., 2010).

As condições ambientais neste ano não foram favoráveis ao aparecimento da doença e, por isso, a severidade em todos os tratamentos foi baixa. É necessário realizar novos trabalhos para verificar a eficácia desses produtos em condições de alta severidade da doença.

\section{CONCLUSÃO}

O fungicida foi o mais eficiente no controle da ferrugem seguido dos tratamentos com Fortaleza ${ }^{\circledR}$, Reforce $\mathrm{Zn}^{\circledR}$, Green Force $\mathrm{S}^{\circledR}$ e Fulland ${ }^{\circledR}$. É necessário realizar novos experimentos para comprovar a eficiência destes produtos como alternativa no controle da ferrugem.

\section{REFERÊNCIAS}

ASSUNÇÃO, M.; TORRES, A.L. Eficácia versus viabilidade econômica do controle químico e genético da ferrugem da folha em trigo. Revista Ciência Rural, Santa Maria, Online, v. 43, n.7, p.1141 - 1146, 2013. Disponível em: http://dx.doi.org/10.1590/S0103-84782013005000094. Doi: 10.1590/S010384782013005000094. 
BARCELOS, A.L. As ferrugens do trigo no Brasil. In: OSÓRIO, E.A. (ed.). Trigo no Brasil. Campinas: Fundação Cargill, 1982. p.377-419.

BIOTRIGO GENÉTICA. Cultivar TBIO Iguaçu, 2013. Disponível em: http://www.biotrigo.com.br/cultivares/internaCultivar.php?empresa $=1 \& \mathrm{id}=15$ Acesso: 01 set. 2013.

BUFFARA, C.R.S.; ANGELOTTI, F.; TESSMANN, D.J.; SOUZA, C.D.; VIDA, J.B. Atividade de fosfito de potássio na pré e pós-infecção de Phakospora euvitis em folhas de videira. Revista Semina: Ciências Agrárias, Londrina. V.34, n.6, p. 33333340, $2013 . \quad$ Disponível em: https://www.researchgate.net/publication/274655517_Atividade_de_fosfito_de_potas sio_na_pre_e_pos-infeccao_de_Phakopsora_euvitis_em_folhas_de_videira. Doi: $10 . \overline{5} 433 / 16 \overline{7} 9-0359.2013 v 34 \mathrm{n} 6 \bar{S} u p l 1 p 3333$

CAMPONOGARA, A.; GALLIO, E.; BORBA, W.F.; GEORGIN, J. O atual contexto da produção de trigo no Rio Grande do Sul. Revista eletrônica em gestão, educação e tecnologia ambiental, Santa Maria. V.19, n.2, p. 246-257. Disponível em: https://periodicos.ufsm.br/reget/article/view/15437/pdf_1.

DOI: $105902 / 2236117015437$.

CONAB, Companhia Nacional de Abastecimento. Acompanhamento da safra Brasileira, Safra 2016/2017- Março, 2017. Disponível em: http://www.conab.gov.br/OlalaCMS/uploads/arquivos/17 $03 \quad 14 \quad 1528 \quad 33$ boletim graos marco 2017bx.pdf Acesso: 02 mar. 2017.

FERREIRA, D.F. SISVAR: Um programa para análises e ensino de estatística. Revista Symposium, v.6, p.36- 41, 2008.

GADAGA, S. J. C.; ABREU, M. S.; RESENDE, M. L. V.; RIBEIRO JUNIOR, P. M. Phosphites for the control of anthracnose in common bean. Pesquisa Agropecuária Brasileira, Brasília, v.52, n.1, p.36-44, jan. 2017. Disponível em: http://dx.doi.org/10.1590/S0100-204X2017000100005. Doi: 10.1590/S0100204X2017000100005.

GOOGLE EARTH. Programa Google Earth, 2007. Image Landsat. Data imagem: 02 de abril de 2017.

GULART, C.A.; DEBORTOLLI, M.; MADALOSSO, M.; BALARDIN, R.; SANTOS, P.S.; CORTE, G.D.; LENZ, G. Espectro de gotas de pulverização e controle de doenças em duas cultivares de trigo. Revista Ciência Rural, Santa Maria. V. 43, n.10, p. 1747-1753, 2013. Disponível em: http://dx.doi.org/10.1590/S010384782013001000003. Doi: 10.1590/S0103-84782013001000003.

MORALES, R.G.F.; SANTOS, I.; TOMAZELI, V.N. Influência da nutrição mineral foliar sobre doenças da parte aérea da cultura do trigo. Revista Ceres, Viçosa. V.59, n.1, p.71-76, 2012. Disponível em: http://dx.doi.org/10.1590/S0034737X2012000100010. Doi: 10.1590/S0034-737X2012000100010. 
ROSA, R.C.T.; COELHO, R.S.B.; TAVARES, S.C.C.H.; CAVALCANTI, V.A.L.B. Efeito de indutores no controle de míldio em Vitis labrusca. Summa Phytopathol., Botucatu, v. 33, n. 1, p. 68-73, 2007. Disponível em: http://dx.doi.org/10.1590/S010054052007000100010. Doi: 10.1590/S0100-54052007000100010.

SEAB/DERAL- Secretaria de Estado da Agricultura e do Abastecimento/Departamento de economia rural. Trigo - Análise da Conjuntura Agropecuária, fevereiro de 2013. Disponível em: <http://www.agricultura.pr.gov.br/arquivos/File/deral/ Prognosticos/Trigo_2013.pdf>.

SHANER, G.; FINNEY, R.E. The effects of nitrogen fertilization on the expression of slowmildwing in knox wheat. Phytopathology, v.67, p.1051-1055, 1977. Disponível em:

https://www.apsnet.org/publications/phytopathology/backissues/Documents/1977Arti cles/Phyto67n08_1051.PDF.

SILVA, N.C.N.; RESENDE, M.L.V.; PEREIRA, R.B.; SILVA, A.C.; RIBEIRO JUNIOR, P.M.; SILVA JUNIOR, M.B. Fertilizantes foliares, extrato vegetal e fungicida no controle do oídio do eucalipto em minijardim clonal. Reunião Regional da SBPC em Lavras / MG - 2010. Disponível em: http://www.sbpcnet.org.br/livro/lavras/resumos/1442.pdf.

TÖFOLI, J.G.; MELLO, S.C.; DOMINGUES, R.J. Efeito do fosfito de potássio isolado e em mistura com fungicidas no controle da requeima do tomateiro. Arquivo do Instituto Biológico, São Paulo. V.79, n. 2, p. 201-208, 2012. Disponível em: http://dx.doi.org/10.1590/S1808-16572012000200008. Doi: 10.1590/S180816572012000200008.

TORMEN, N.R.; LENZ, G.; MINUZZI, S.G.; UEBEL, J.D.; CEZAR, H.S.; BALARDIN, R.S. Reação de cultivares de trigo à ferrugem da folha e mancha amarela e responsividade a fungicidas. Revista Ciência Rural, Santa Maria. V.43, n.2, p. 239246, 2013. Disponível em: http://dx.doi.org/10.1590/S0103-84782013000200008. Doi: 10.1590/S0103-84782013000200008.

ZADOKS, J.C.; CHANG, T.T.; KONZAK, C.F. A decimal code for growth stages of cereals. Weed Res, v. 14, p. 415-421, 1974. 